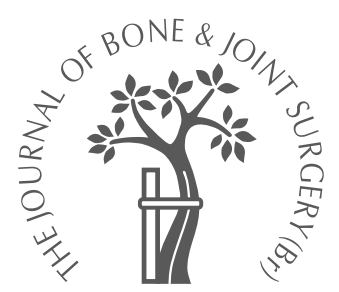
P. Dixon,
E. N. Parish,
B. Chan,
J. Chitnavis,
M. J. Cross

From the Australian Institute of MusculoSkeletal Research, Sydney, Australia

P. Dixon, MBBCh, FRCS Orth, Orthopaedic Fellow E. N. Parish, MHSc, Research Assistant

B. Chan, MBBS, FRCS Ed (Orth), FHKAM (Orth), Orthopaedic Fellow

J. Chitnavis, MChir, FRCS Orth, Orthopaedic Fellow M. J. Cross, OAM, MBBS, MD, FRACS, Consultant Knee Surgeon

Australian Institute of Musculo-Skeletal Research, 286 Pacific Highway, Crows Nest, Sydney 2065, Australia.

Correspondence should be sent to Dr M. J. Cross.

(c)2004 British Editorial Society of Bone and Joint Surgery doi:10.1302/0301-620X.86B2 $14341 \$ 2.00$

$J$ Bone Joint Surg $[\mathrm{Br}]$ 2004;86-B:200-4.

Received 20 March 2003

Accepted after revision

20 August 2003

\section{Hydroxyapatite-coated, cementless total knee replacement in patients aged 75 years and over}

We have carried out a prospective study comparing the results at five years in patients older than 75 years of age undergoing hydroxyapatite-coated, cementless total knee replacement (TKR) with those who were younger. The Knee Society clinical rating scores were recorded before and after operation. Of 559 patients undergoing TKR, 135 were in the elderly age group. The knee scores at five years or more showed comparable results, with patients under 75 years of age reaching a score of 183 and those aged 75 years or over reaching 174. These differences were predominantly due to the functional component of the score. We conclude that elderly patients do just as well as the younger group using this prosthesis.

Total knee replacement (TKR) is an effective procedure even when undertaken in the elderly. ${ }^{1-5}$ In general, survival of uncemented prostheses is comparable with their cemented counterparts at ten years. ${ }^{6}$ Most data available on TKR in the elderly relate to cemented prostheses. The use of uncemented TKR in these patients has been controversial because of concerns regarding the initial fixation of the tibial component, the ability of osteoporotic bone to withstand direct prosthesis-bone load transmission and osseo-integration of the prosthesis. ${ }^{7}$ Hydroxyapatite (HA) has been shown to enhance tibial fixation in a number of studies. ${ }^{8-11}$ We have compared the outcomes in patients over the age of 75 years with a younger group using an uncemented HAcoated TKR over the same period.

\section{Patients and Methods}

All patients undergoing primary TKR, carried out by the senior author (MJC) between August 1992 and October 1997, were reviewed. An HA-coated, posterior cruciate ligament retaining, stemless prosthesis was implanted using a standard technique. We recorded the Knee Society clinical rating scores before and at one and five years after operation. The clinical rating score is divided into knee and function components, each worth a total of 100 points, giving a total score of $200 .{ }^{12}$ Independent examiners, either an orthopaedic surgeon completing a fellowship programme or a qualified researcher, conducted the clinical examinations for the study. Weight-bearing anteroposterior, lateral and skyline patella radiographs were taken routinely at five years and examined by a radiologist to determine evidence of loosening.

The prosthesis used was the uncemented Active (DJ Ortho, Sydney, Australia). The femoral component (CoCrMo) features recessed heat sintered beads on the deep surface. The tibial component (Ti6A14V) is designed with four press fit lugs on its under surface, through which screws are inserted. The lugs provide initial rotational stability and the screws prevent lift off. The under surface of the tibial component is also recessed and coated with heat sintered beads (pore size 250 to $500 \mu \mathrm{m}$ ). The surfaces of both components are coated with HA. This is applied using a plasma spray technique to a thickness of $70 \mu \mathrm{m}$ (crystallinity $75 \%$, porosity $20 \%$ ), which facilitates penetration of osteoblast into the porous beads without blocking the pores.

The senior author (MJC) emphasises certain points regarding the surgical technique, especially in the elderly patient. Cortical support of the tibial tray is essential and the tibial base plate was sized to maximise this. Holes to accept the lugs on the under surface of the tibial tray were drilled in a reverse manner in order to impact cancellous bone. Any surface defects of the bone were filled using autologous cancellous graft salvaged from previous bone cuts. The decision on whether to replace the patella, using a cemented all polyethylene component, was taken during the operation.

For statistical analysis we used the Statistical Package for the Social Sciences (SPSS, version 10.0, Chicago, Illinois) with data assumed to 
Table I. Details of the 559 patients who underwent a TKR

\begin{tabular}{lccc}
\hline Age (years) & $\begin{array}{l}\text { Younger group } \\
\text { (aged }<75 \text { years) }\end{array}$ & $\begin{array}{l}\text { Older group } \\
\text { (aged } \geq 75 \text { years) }\end{array}$ & p value \\
\hline Mean & 66 & 79 \\
Range & 33 to 74 & 75 to 83 & \\
Gender & & & 0.101 \\
$\quad$ Male (\%) & $207(49)$ & $55(41)$ & 0.574 \\
$\quad$ Female (\%) & $217(51)$ & $80(59)$ & 0.063 \\
Number of simultaneous, bilateral procedures (\%) & $143(34)$ & $42(31.0)$ & 0.001 \\
Number of staged bilateral procedures (\%) & $56(13)$ & $11(8)$ & $3(2.2)$ \\
Number of previous high tibial osteotomies (\%) & $26(6.1)$ & $23(17.0)$ & \\
Number of deaths since surgery (\%) & $25(5.9)$ & & \\
\hline
\end{tabular}

Table II. The number and percentage of patients, and their diagnosis

\begin{tabular}{|c|c|c|c|c|}
\hline \multirow[b]{2}{*}{ Diagnosis } & \multicolumn{2}{|c|}{$\begin{array}{l}\text { Younger group } \\
\text { (aged }<75 \text { years) }\end{array}$} & \multicolumn{2}{|c|}{$\begin{array}{l}\text { Older group } \\
\text { (aged } \geq 75 \text { years) }\end{array}$} \\
\hline & Number & Percentage & Number & Percentage \\
\hline Osteoarthritis & 398 & 94 & 123 & 91 \\
\hline Rheumatoid arthritis & 14 & 3 & 6 & 4.5 \\
\hline Psoriatic arthritis & 6 & 1.5 & 0 & 0 \\
\hline Other* & 6 & 1.5 & 6 & 4.5 \\
\hline
\end{tabular}

* including Paget's disease, trauma, acromegaly, haemachromatosis, osteonecrosis, and osteomyelitis

be non-parametric. Significance was recorded at $\mathrm{p}<0.05$. Differences between patient complications, diagnosis and descriptive data were analysed using Pearson chi-squared analysis. The Knee Society clinical rating scores were analysed using an independent Student's $t$-test.

\section{Results}

Between August 1992 and October 1997, 811 TKRs were undertaken on 559 patients. We divided the patients into two groups according to age, those aged 75 years or more and those aged less than 75 years. Details of the 135 patients in the older group and the 424 in the younger group are shown in Table I. Osteoarthritis was the principal diagnosis (Table II) but with a greater number of inflammatory arthropathies in the younger group $(\mathrm{p}=0.107)$. There were 67 staged bilateral TKRs, 56 in the younger group and 11 in the older group (Table I). Follow-up ranged from five to ten years. The mean follow-up was for 7.1 years in the older group and 6.9 years in the younger.

The mean knee score improved from 96 before surgery to 183 at five years in the younger group and from 94 before surgery to 174 at five years in the older (Table III). The mean range of knee flexion was the same in both groups and reached $113^{\circ}$ at five years. Only one patient $(0.7 \%)$ developed a deep infection in the older group compared with $13(3.1 \%)$ in the younger group. Further surgery was required in 37 patients in the younger group and five in the older respectively (Table IV). Medical complications are documented in Table V and Figure 1. There were no differences between the groups in regard to the rate of complica-

Table III. Mean pre-operative and post-operative knee scores and range of flexion for the 559 patients who underwent TKR

\begin{tabular}{|c|c|c|c|c|c|c|}
\hline & \multicolumn{3}{|l|}{$\begin{array}{l}\text { Younger group } \\
\text { (aged }<75 \text { years) }\end{array}$} & \multicolumn{3}{|l|}{$\begin{array}{l}\text { Older group } \\
\text { (aged } \geq 75 \text { years) }\end{array}$} \\
\hline & Pre-operatively & $\begin{array}{l}\text { At one-year } \\
\text { follow-up }\end{array}$ & $\begin{array}{l}\text { At five-year } \\
\text { follow-up }\end{array}$ & Pre-operatively & $\begin{array}{l}\text { At one-year } \\
\text { follow-up }\end{array}$ & $\begin{array}{l}\text { At five-year } \\
\text { follow-up }\end{array}$ \\
\hline \multicolumn{7}{|l|}{ Knee score } \\
\hline Mean & 96 & 183 & 183 & 94 & 178 & 174 \\
\hline Clinical & 41 & 91 & 94 & 35 & 91 & 92 \\
\hline Range of flexion $\left({ }^{\circ}\right)$ & 6 to 113 & 1 to 112 & 1 to 113 & 6 to 113 & 1 to 112 & 1 to 113 \\
\hline
\end{tabular}

Table IV. Complications requiring surgery in the two age groups following TKR $(p=0.486)$

\begin{tabular}{lcl}
\hline Complication & $\begin{array}{l}\text { Younger group } \\
\text { (aged }<\mathbf{7 5} \text { years) }\end{array}$ & $\begin{array}{l}\text { Older group } \\
\text { (aged } \geq \mathbf{7 5} \text { years) }\end{array}$ \\
\hline Revision & 6 & 0 \\
Change of polythene liner & 2 & 0 \\
Deep infection & 13 & 1 \\
Subsequent patella replacement & 11 & 3 \\
Arthrolysis & 4 & 1 \\
Periprosthetic fracture & 1 & 0 \\
\hline
\end{tabular}


Table V. Medical complications seen in the two age groups following TKR $(p=0.233$ )

\begin{tabular}{llcc}
\hline Complication & & $\begin{array}{c}\text { Younger group } \\
\text { (aged < 75 years) }\end{array}$ & $\begin{array}{l}\text { Older group } \\
\text { (aged } \geq 75 \text { years) }\end{array}$ \\
\hline Cardiac & Peri-operative death & $0(0)$ & $1(0.7)$ \\
& Myocard Infarct & $3(0.7)$ & $1(0.7)$ \\
& Arrhythmia & $13(3.1)$ & $3(2.2)$ \\
Thromboembolic & Pulmonary embolism & $13(3.1)$ & $2(3.0)$ \\
& Symptomatic deep vein thrombosis & $2(0.5)$ & $12(8.9)$ \\
Other* & Asymptomatic deep vein thrombosis & $27(6.4)$ & $13(9.6)$ \\
\hline
\end{tabular}

* oedema, bowel obstruction, confusion, urinary tract infection, nausea, hiccoughs, and pressure sores

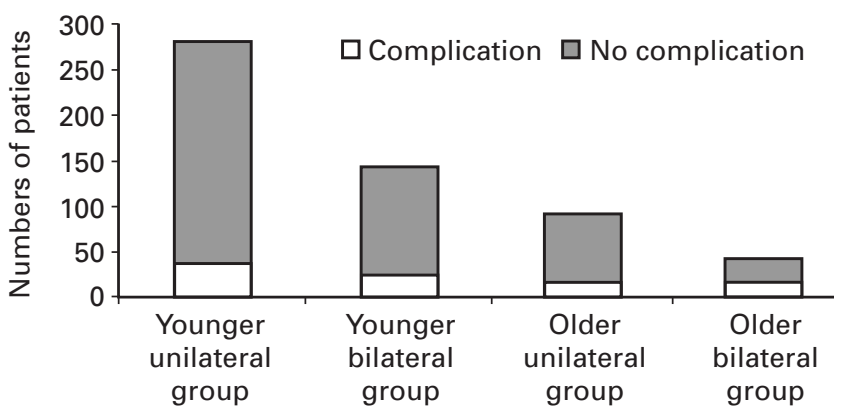

Fig. 1

Risk of complication when undertaking simultaneous bilateral TKRs in younger and older groups. Complication rates were $13.9 \%$ in the younger unilateral group, $18.2 \%$ in the younger bilateral group, $20.4 \%$ in the older unilateral group and $35.7 \%$ in the older bilateral group.

tions requiring surgery or medical complications $(\mathrm{p}=0.486$ and $\mathrm{p}=0.233$ respectively).

\section{Discussion}

The use of uncemented components for TKR in the elderly has been questioned due to concerns about fixation to osteoporotic bone and the ability of the bone to withstand direct transmission of force.

The theoretical advantages of the uncemented design are preservation of bone stock, ease of revision, decreased operative time and potentially fewer complications. Cementless prostheses for TKR have been available for many years, but the early results were compromised by poor design which was related principally to the use of femoral components made from titanium alloy and metal backed patellar prostheses. ${ }^{3,13,14}$ The results of uncemented and cemented TKRs, using a prosthesis of proven design, have shown no difference in clinical outcome at ten years. ${ }^{6}$

$\mathrm{Li}$ and Nilsson ${ }^{7}$ demonstrated that decreased bone mineral density led to increased subsidence and lift-off of the tibial base plate. Concerns regarding the fixation of the tibial prosthesis in osteoporotic bone are the basis of reluctance to use uncemented tibial fixation in the elderly. Tibial cortical cover is essential in order to prevent subsidence of the tray. ${ }^{10,13}$ Attention to detail in this part of the operation does decrease this risk. We also believe that the technique of reverse drilling the tibial lugholes, compressing the under- lying cancellous bone, is important in order to enhance screw fixation and improve resistance to lift-off.

Hydroxyapatite has been shown to reduce micromovement in the tibial component in a number of studies ${ }^{8,9}$ and to compare favourably with that achieved when using a cemented technique. ${ }^{10}$ Although we did not compare the results with those using a non-HA coated prosthesis, we believe that our findings demonstrate that HA coating combined with a meticulous operative technique does produce good results in the elderly (Fig. 2). This is comparable with those reported previously described using cemented prostheses. $^{1-3}$

The Knee Society clinical rating score combines clinical and functional results. Previous studies have shown that elderly patients, although improving significantly in both components, do not do as well regarding function. ${ }^{1,2}$ Interestingly, our study demonstrates a significant difference in both knee and function score in the older group (Table III; $\mathrm{p}<0.05)$. The difference in knee scores, a mean of nine points, is probably due to factors of co-morbidity relating to reduced mobility, and has been noted before. ${ }^{1,15}$ The slightly lower scores at five years in the older group points to them having increasing co-existent conditions, limiting mobility. The difference in the clinical score is only a mean of two points, which is of little clinical significance, although it reaches statistical significance. It should also be observed that the pre-operative scores for the older group were less than those for the younger group.

As could be expected, our study demonstrates a significant difference in mortality between the groups (Table I), but we do not feel this impacts on other results as numbers in both groups remain high. Some authors have reported an increased rate of medical complications after TKR in the elderly population, principally in the form of post-operative confusion. ${ }^{4,5}$ Although our study reveals no statistical difference between the two groups as far as medical complications are concerned $(\mathrm{p}=0.233)$, it does demonstrate a trend towards more complications in the elderly group. However, this trend is mainly limited to the less serious, self-limiting complications (Table V). The specialist nature of the centre at which this study was carried out, with the majority of patients being assessed by a consultant physician prior to surgery, may not be reproduced in other places. The fact that cement was not used, and the 


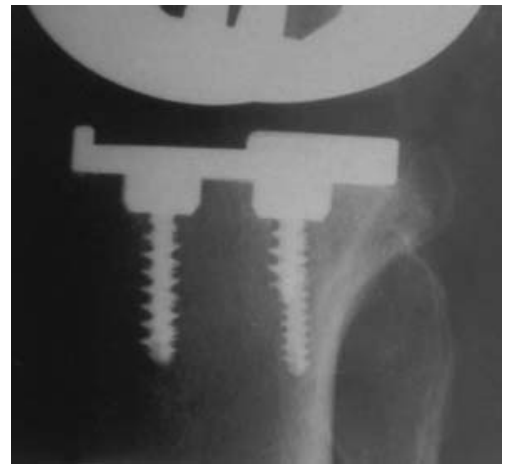

Fig. 2a

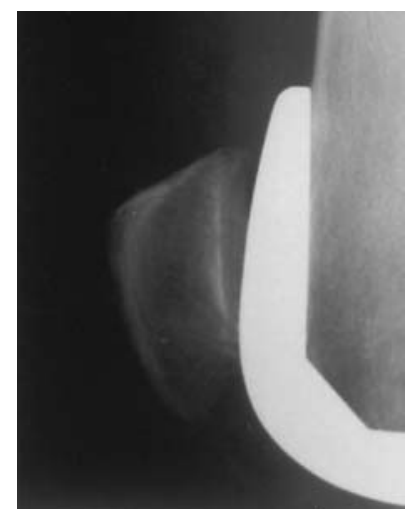

Fig. 2c



Fig. 2b

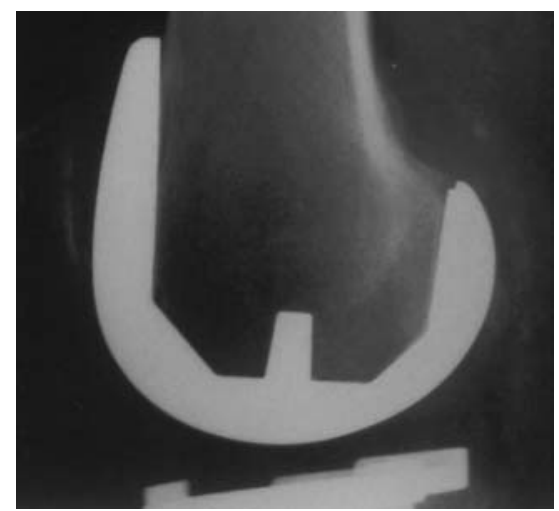

Fig. 2d

Radiographs showing interface views at five years after TKR in a patient aged over 75 years.

decreased tourniquet time associated with this, may also contribute. Complications requiring further surgery revealed no significant difference between the groups, but there is a trend towards more frequent deep infection and revision in the younger age group. The reason why these rates may be higher in the younger age group is unclear. Previous studies have demonstrated an increased risk of complications when undertaking simultaneous bilateral TKR. ${ }^{16-18}$ Our study demonstrates this in both groups (Fig. 2 ). It is interesting that although the risk of complications in each group is increased for simultaneous, bilateral TKR, it is not double the risk. To assess the risks accurately, comparison should be made between a group undergoing staged, bilateral TKR, rather than with a group undergoing unilateral TKR.

The results of HA-coated, uncemented TKR in the elderly are clinically comparable with those in a younger group giving a reliable, effective outcome at five years. The rate of complications in the older group are greater, but they do not reach statistical significance. These are mainly minor, self-limiting, medical conditions which do not impact on the final outcome.
No benefits in any form have been received or will be received from a commercial party related directly or indirectly to the subject of this article.

\section{References}

1. Zicat B, Rorabeck CH, Bourne RB, Devane PA, Nott L. Total knee arthroplasty in the octogenarian. J Arthroplasty 1993;8:395-400.

2. Brander VA, Malhotra S, Jet J, Heinemann AW, Stulberg SD. Outcome of hip and knee arthroplasty in persons aged 80 years and older. Clin Orthop 1997;345: 67-78.

3. Birdsall PD, Hayes JH, Cleary R, et al. Health outcome after total knee replacement in the very elderly. J Bone Joint Surg [Br] 1999;81-B:660-2.

4. Hosick WB, Lotke PA, Baldwin A. Total knee arthroplasty in patients 80 years of age and older. Clin Orthop 1994;299:77-80.

5. Laskin RS. Total knee replacement in patients older than 85 years. Clin Orthop 1999; 367:43-9.

6. Khaw FM, Kirk LMG, Morris RW, Gregg PJ. A randomised, controlled trial of cemented versus cemented press-fit condylar total knee replacement. J Bone Joint Surg [Br] 2002;84-B:658-66.

7. Li MG, Nilsson KG. The effects of the preoperative bone quality on the fixation of the tibial component in total knee arthroplasty. J Arthroplasty 2000;15:744-53.

8. Onsten I, Norqvist A, Carlsson AS, Bejaskov J, Shott S. Hydroxyapatite augmentation of the porous coating improves fixation of tibial components: a randomised RSA study in 116 patients. J Bone Joint Surg [Br] 1998;80-B:417-25.

9. Toksvig-Larsen S, Jorn LP, Ryd L, Lindstrand A. Hydroxyapatite-enhanced tibial prothetic fixation. Clin Orthop 2000;370:192-200.

10. Nelissen RG, Valstar ER, Rozing PM. The effect of hydroxyapatite on the micromotion of total knee prostheses: a prospective, randomised, double-blind study. J Bone Joint Surg [Am]1998;80-A: 1665-72. 
11. Regner L, Carlsson L, Karrholm J, Herberts $\mathbf{P}$. Tibial component fixation in porous- and hydroxyapatite-coated total knee arthroplasty. J Arthroplasty 2000;15: 681-9.

12. Insall JN, Door MD, Scott RD, Scott WN. Rationale of the knee society clinical rating system. Clin Orthop 1989;248:13-4.

13. Berger RA, Lyon JH, Jacobs JJ, et al. Problems with cementless total knee arthroplasty at 11 years follow-up. Clin Orthop 2001;392:196-207.

14. Crites BM, Berend ME. Metal-backed patellar components: a brief report on 10year survival. Clin Orthop 2001;388:103-4.
15. Adam RF, Noble J. Primary total knee arthroplasty in the elderly. J Arthroplasty 1994:9:495-7.

16. Adili A, Bhandari M, Petrucelli D, De Beer J. Sequential bilateral total knee arthroplasty under 1 anaesthetic in patients $>$ or $=75$ years old: complications and functional outcomes. J Arthroplasty 2001;16: 271-8.

17. Lombardi AV, Mallory TH, Fada RA, et al. Simultaneous bilateral total knee arthroplasties: who decides? Clin Orthop 2001;392:319-29.

18. Lane GJ, Hozack WJ, Shah S, et al. Simultaneous bilateral versus unilateral total knee arthroplasty: outcomes analysis. Clin Orthop 1997; 345:106-12. 